\title{
Letras em empenas cegas na cidade de São Paulo no início do século XX: um estudo piloto
}

\author{
Letters in blank façades in São Paulo city in the early 20th century: a pilot study
}

\author{
Camila Catarina da Silva Flores, Priscila Lena Farias
}

memória gráfica, paisagens tipográficas, espaço público

\begin{abstract}
Empenas cegas foram utilizadas como expositoras de variados tipos de anúncios e mensagens no início do século XX. Este período corresponde à fase inicial de verticalização da capital paulista, na qual os primeiros prédios surgem e ocorre uma gradual transformação da morfologia urbana da cidade. São Paulo passa por mudanças arquitetônicas, industriais e publicitárias de maneira síncrona, e isso se reflete na ocupação das empenas cegas e na configuração da paisagem tipográfica da cidade. Partindo de registros fotográficos realizados nas primeiras décadas do século $X X$, o estudo piloto descrito neste artigo demonstra como é possível identificar elementos tipográficos em empenas cegas e compará-los com aqueles presentes em impressos do mesmo período, tendo em vista uma compreensão mais completa da cultura tipográfica vigente neste recorte temporal.
\end{abstract}

graphic memory, typographic landscapes, public space

Blank façades were used as exhibitors for various types of advertisements and messages in the early 20th century. This period corresponds to the initial phase of verticalization of the São Paulo capital, in which the first buildings appear and a gradual transformation of the urban morphology of the city occurs. São Paulo undergoes synchronous architectural, industrial and advertising changes, and this is reflected in the occupation of blank façades and in the configuration of the city's typographic landscape. Starting from the photographic records made in the first decades of the twentieth century, the pilot study described in this article demonstrates how it is possible to identify typographic elements in blank façades and compare them with those present in printed matter from the same period, aiming at a more complete understanding of the typographic culture current in this time frame.

\section{Introdução}

O estudo piloto descrito neste artigo teve como objetivo geral descrever e analisar o uso de letras, números e sinais em anúncios fixados em empenas cegas como parte da cultura visual paulistana na primeira metade do século $X X$, contribuindo para a compreensão da memória gráfica e da cultura da impressão na cidade. Teve também, como objetivos específicos, compreender as origens do uso de empenas cegas enquanto suporte para a publicidade em São Paulo, identificar padrões e tendências nos desenhos de letras utilizados nestes suportes na cidade de São Paulo no início do século XX. 
Segundo Segawa (2000, p. 14), durante o início do século XX a cidade de São Paulo iniciou processo de verticalização da paisagem urbana. As empenas cegas erguidas nesse período serviram como suportes para anúncios comerciais que podem ser entendidos como exemplos de tipografia comercial (Farias, 2016, pp.141-150).

Vincenzo Pastore, Theodor Preising e Guilherme Gaensly são alguns dos fotógrafos que registraram a cidade na época (Lemos, 2016). Esses profissionais tiveram contato com a paisagem urbana de São Paulo em diferentes períodos da primeira metade do século XX, reunindo um conjunto de imagens que acompanham a construção e desconstrução da cidade e apresentam empenas cegas integradas à paisagem urbana paulistana.

\section{Coleta de dados}

A busca por materiais fotográficos dentro do recorte temporal — primeira metade do século $X X-$ e geográfico - capital paulista - em acervos públicos digitalizados foi um primeiro exercício de investigação. Dentro do conjunto de fotografias encontradas nos acervos, foram selecionadas aquelas que continham registros de empenas cegas. Os principais acervos consultados foram:

- Hemeroteca Digital da Biblioteca Nacional;

- Acervo Estadão - O Estado de S. Paulo;

- Museu Paulista da USP;

- Museu da Cidade;

- Instituto Moreira Salles;

- Arquivo Nacional.

Foram encontradas 30 fotografias nos acervos listados. Destas, foram selecionadas 20 fotografias que registravam empenas cegas contendo elementos tipográficos. Para o estudo piloto apresentado neste artigo, foram destacadas 2 destas fotografias, que representam períodos diferentes dentro do recorte da pesquisa.

\section{Tratamento e análise de dados}

O tratamento de dados consistiu na nomenclatura e organização das imagens em pastas ou álbuns digitais, e no tratamento destas imagens. As fotografias contendo empenas foram tratadas para obter-se melhor visualização. Este tratamento consistiu na edição das peças fotográficas (de $300 \mathrm{dpi}$ ) e na análise da qualidade de cada uma das imagens em um software editor de imagens - no caso, o Adobe Photoshop. Para melhor compreensão, esse processo foi dividido em cinco partes:

- Separação de planos: identificação de quais planos da fotografia seriam utilizados;

- Alinhamento: Linhas guia foram inseridas para identificar perpendicularidades e referências na fotografia, facilitando o alinhamento das letras marcadas nas empenas; 
- Perspectiva: a perspectiva das imagens foi ajustada, permitindo enquadrar e alinhar as letras no espaço das empenas;

- Recorte: os planos identificados foram recortados, permitindo ajustes de contraste;

- Contraste: as configurações de contraste foram manipuladas a fim de realçar os contornos das letras, evidenciando as características de seu desenho.

As letras encontradas nas empenas foram então comparadas com aquelas presentes em impressos do mesmo período, buscando-se identificar tendências e peculiaridades. $\mathrm{O}$ repertório das famílias tipográficas utilizadas em impressos paulistanos do século XIX e início do século XX, que consta na plataforma 'Tipografia Paulistana' foi definido como principal referência para a descrição das letras encontradas a para a interpretação dos dados.

\section{Resultados}

A tabela 1 apresenta informações sobre as fotografias selecionadas para a pesquisa, numeradas de 1 a 20, e organizadas cronologicamente. Nas primeiras cinco colunas da planilha de coleta de dados pode-se visualizar a autoria da fotografia, a variação das datas dentro da seção temporal estabelecida, o logradouro e a quantidade de recortes a que a fotografia foi submetida. As datas dos registros fotográficos variam de 1902 a 1950.

Tabela 1. Reprodução das 20 linhas e das primeiras colunas da planilha de fotografias selecionadas.

\begin{tabular}{lllll}
\hline Fotografia & Autoria & Data & Logradouro & Recortes \\
\hline 1 & Guilherme Gaensly & 1902 & Rua Florêncio de Abreu & 1 \\
2 & desconhecida & 1904 & Centro & 4 \\
3 & Fréderic Manuel & 1906 & Rua Direita & 1 \\
4 & Vincenzo Pastore & 1908 & Rua Direita & 1 \\
5 & Vincenzo Pastore & 1912 & Largo da Sé & 1 \\
6 & Vincenzo Pastore & 1912 & Largo da Sé & 1 \\
7 & desconhecida & 1922 & desconhecido & 2 \\
8 & Hugo Zanella & 1922 & Centro & 2 \\
9 & Gustavo Prugner & 1930 & Avenida São João & 3 \\
10 & Theodor Preising & 1930 & Largo da Sé & 1 \\
11 & Theodor Preising & 1933 & desconhecido & 5 \\
12 & Claude Lévi-Strauss & 1937 & Avenida São João & 1 \\
13 & Claude Lévi-Strauss & 1937 & Avenida São João & 1 \\
14 & Edgard E. de Souza & $1930-1939$ & Centro & 3 \\
15 & Hildegard Rosenthal & 1940 & Praça da Sé & 1 \\
16 & Hildegard Rosenthal & 1940 & Praça da Sé \\
17 & Thomaz Farkas & 1940 & Edifício Altino Arantes & 3 \\
18 & desconhecida & 1940 & R. Dom José de Barros & 1 \\
19 & Benassi & $1948-1950$ & Av. São João & 1 \\
20 & Fotolabor & 1950 & Av. São João & 1 \\
& & & & 35 \\
\hline
\end{tabular}


Figura 1. Fotografia 2. Centro de São Paulo. Autoria: desconhecida. 1904. Fonte: Estadão.

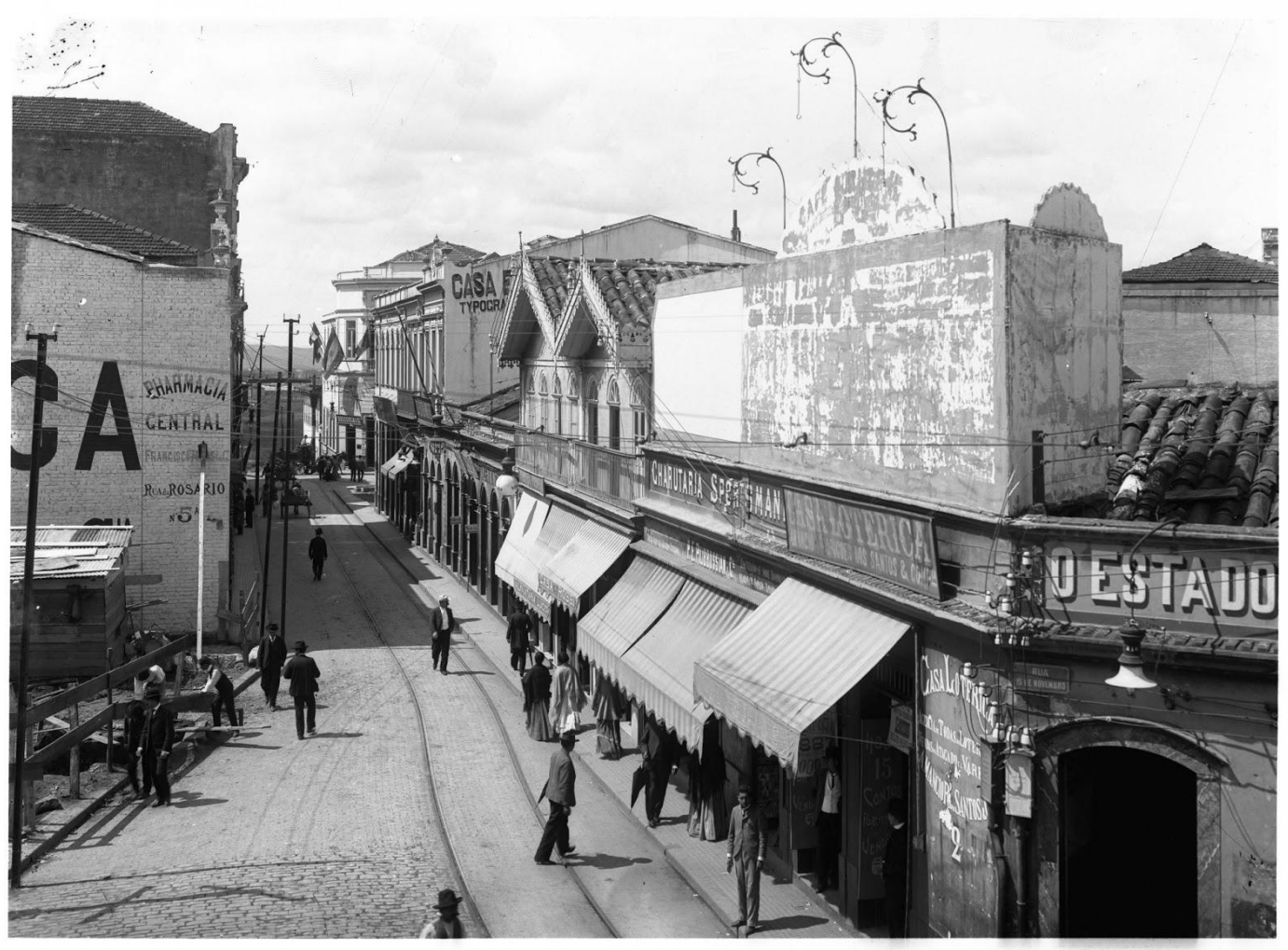

A figura 1 apresenta uma fotografia que possui dois planos distintos, que foram trabalhados durante a etapa de tratamento e edição de imagens. Nesses planos, foram delimitadas as empenas. Nos quatro recortes selecionados foi possível notar diferentes estilos tipográficos. Letras serifadas, grotescas, fantasia, escriturais representam algumas características encontradas e, ao analisar e realizar uma comparação com famílias tipográficas que estão catalogadas na plataforma 'Tipografia Paulistana', algumas observações foram realizadas (Tabela 2). 
Tabela 2. Recortes da Fotografia 2 e comparações com o site 'Tipografia Paulistana'.

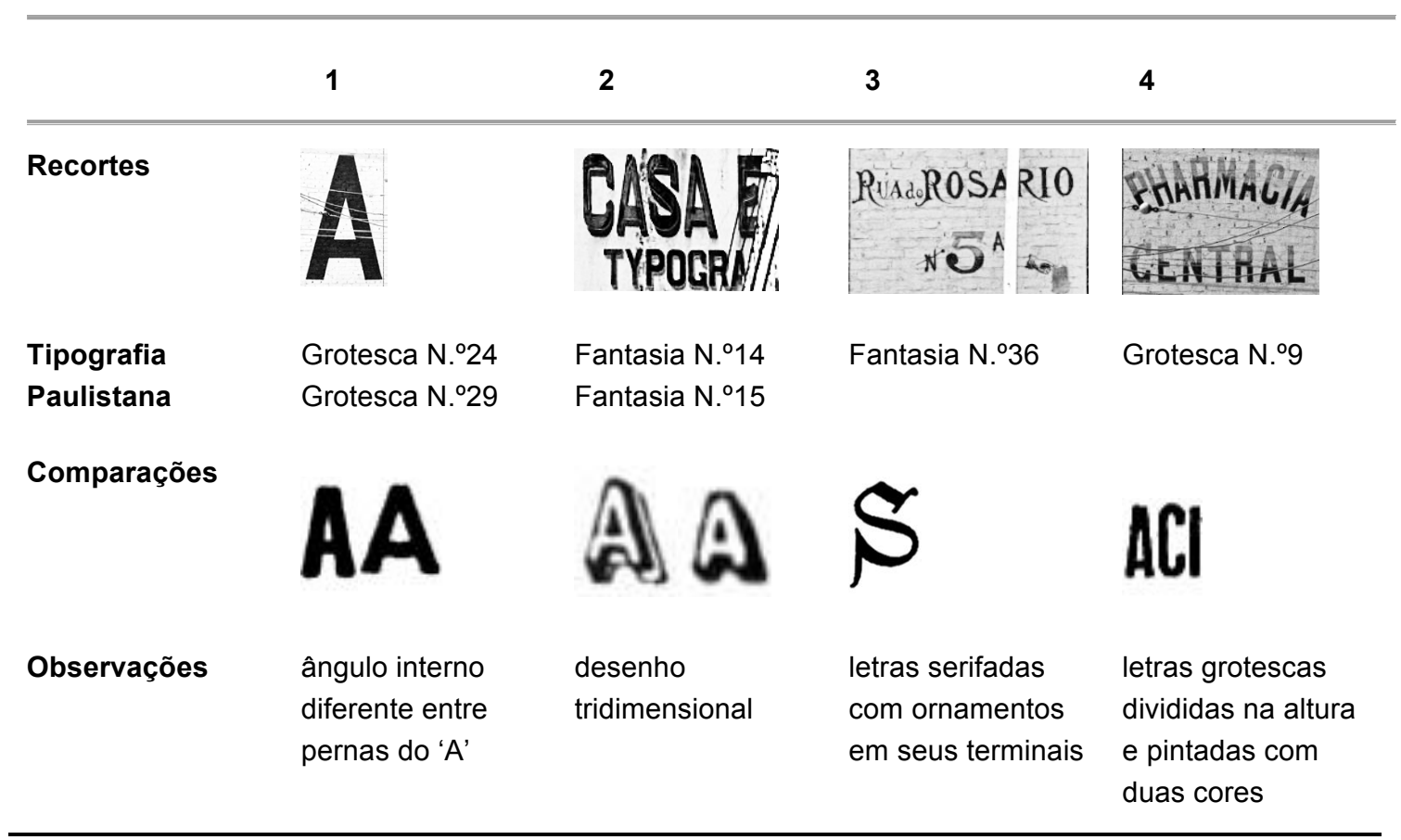

Figura 2. Fotografia 17. Vista para o Edifício Altino Arantes. Autoria: Thomaz Farkas. 1940. Fonte: Instituto Moreira Salles.

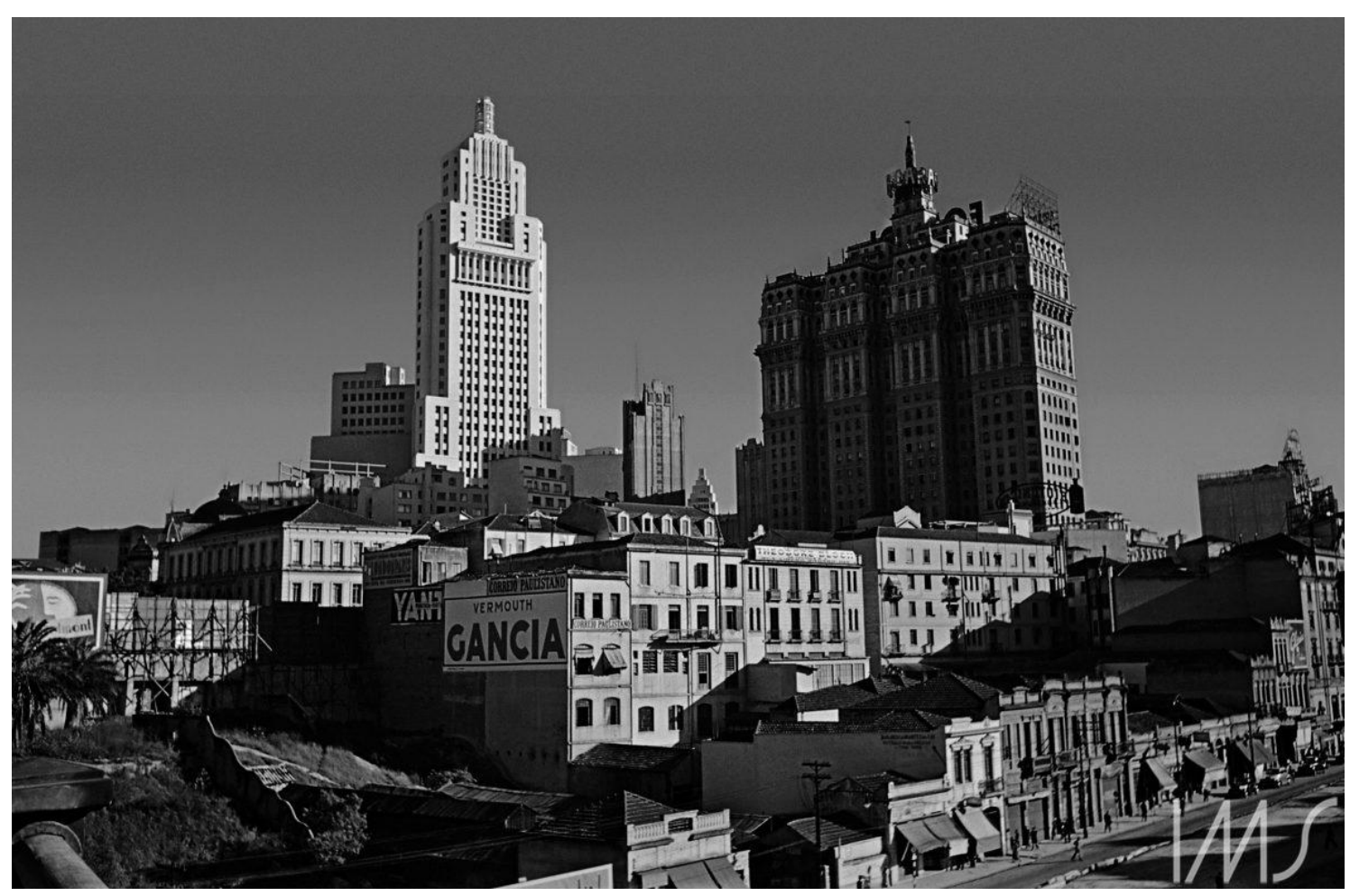

A figura 2 apresenta apenas um plano que foi tratado e recortado. Ou seja, todos os recortes (tabela 3 ) foram retirados do mesmo plano/empena. 
Tabela 3. Recortes da Fotografia 17 e comparações com o site 'Tipografia Paulistana'.

1

2

Recortes

VERMOUTH

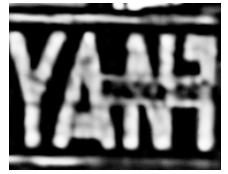

Tipografia Paulistana

Grotesca N. ${ }^{\circ} 24$

Grotesca N. ${ }^{\circ} 04$

Grotesca N. ${ }^{\circ} 29$

Grotesca N. ${ }^{\circ} 31$

\section{Comparações}

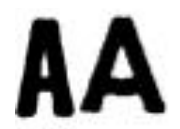

AAN

Observações

ângulo diferente entre pernas do

'A' espessura da letra e ângulo entre pernas menos agudo

\section{Discussão}

Em relação às fotografias encontradas, pôde-se observar que a maioria delas parece ter tido como premissa o registro da urbanidade da cidade, destacando prédios que formam skylines, a movimentação de bondes/carros nas ruas e as pessoas circulando no espaço urbano. De maneira geral, as fotografias encontradas não tinham como tema central as empenas cegas. Foi necessário observar detalhes não aparentemente priorizados pelos fotógrafos, num sentido de busca do micro (as empenas) no macro (o espaço urbano). Apenas uma das fotografias encontradas tinha como prioridade o enquadramento de uma empena: numerada como 8 , datada de 1922 (figura 3). 
Figura 3. Fotografia 8. Centro de São Paulo. Hugo Zanella. 1922.

Fonte: Gonzáles e Novaes 2012, pp.123.

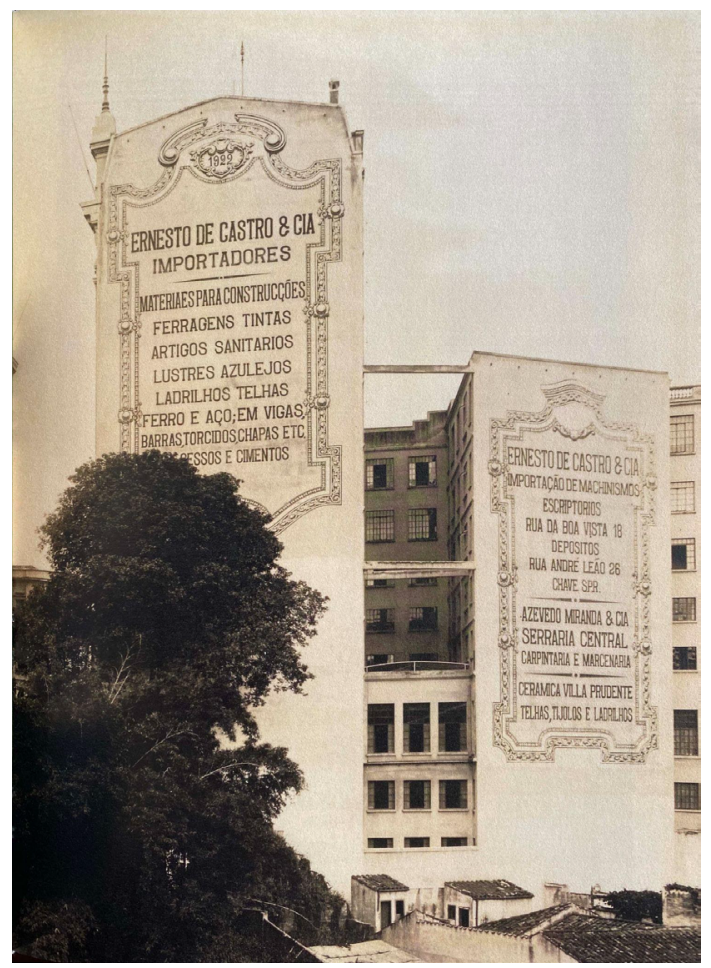

No que se refere aos recortes, as letras que constam nas empenas possuem uma variedade de tamanhos, alinhamentos, estilos de desenho e formas de organização. As mensagens e anúncios também são diversos. As grotescas, no geral, prevalecem em anúncios e as serifadas e letras de fantasia aparecem em mensagens, informes e nomes de rua.

Comparando as letras encontradas nas 2 fotografias com aquelas presentes na plataforma 'Tipografia Paulistana', foi possível notar que as letras inseridas no meio urbano por meio das empenas cegas eram influenciadas pelo repertório tipográfico utilizado em impressos da época, como periódicos, folhetos e outros suportes tipográficos.

No entanto, foi observado que caracteres tipográficos possuem formas já definidas. Na impressão tipográfica, tipos preexistentes, com desenhos que não mudam devido a suas características, materiais são utilizados várias vezes para o mesmo fim. Por outro lado, letristas ou abridores de letras têm liberdade para ajustar e criar novos desenhos antes ou durante o processo de obtenção das letras. Os caracteres abertos por letristas podem, por exemplo, incluir técnicas como o degradê, e ser pintados com mais de uma cor.

\section{Considerações finais}

Desdobramentos futuros da pesquisa incluem a análise de todas as letras presentes nos recortes obtidos a partir das fotografias identificadas, verificando coincidências entre elas e aquelas utilizadas em impressos do mesmo período, buscando identificar relações e/ou tendências, e buscando uma compreensão dos processos pelos quais a cidade estava passando. 
Realizar esse tipo de estudo é um exercício de resgate dos modos de configuração visual de mensagens com importantes contribuições para o estudo do Design da Informação, uma vez que se trata de um período histórico de pioneirismo no que se refere à inserção de mensagens contendo letras pintadas em grande escala no espaço público.

\section{Referências}

Campos, C. M. 2004. Construção e deconstrução do centro paulistano. Ciência e Cultura, v. 56, n. 2, p. 33-37.

Cunha Lima, E. L.; Aragão, I. R.; Farias, P. L. 2011. Catálogos de tipos móveis: contribuições para a história (tipo)gráfica brasileira. In: Anais do $5^{\circ} \mathrm{CIDI}$. Florianópolis: SBDI.

Farias, P.L. 2016. Estudos sobre tipografia: letras, memória gráfica e paisagens tipográficas. Tese de Livre-Docência, FAU USP.

Farias, P.L. 2019. Visualizing data on graphic memory research. In: Selected Readings of the 8th Information Design International Conference: Memories. São Paulo: Blucher.

Farias, P. L.; Aragão, I. R. \& Cunha Lima, E. L. 2012. Unraveling aspects of Brazilian design history through the study of 19th century almanacs and type specimens. In: Conference Proceedings: DRS 2012. Bangkok: Chulalongkorn University.

González, P. \& Novaes, M. A. V. (orgs.) 2012. Siciliano e Silva: engenheiros construtores. São Paulo: Arauco.

Lemos, E. D. 2016. Fotografia profissional, arquivo e circulação: a produção de Theodor Preising em São Paulo (1920-1940). Tese de Doutorado. Universidade de São Paulo.

Segawa, H. M. 2000. Prelúdio da metrópole: arquitetura e urbanismo em São Paulo na passagem do século XIX ao XX. São Paulo: Ateliê Editorial.

Tipografia Paulistana. (10 mai 2021). Tipografia Paulistana: Um acervo digital reunindo imagens dos tipos utilizados nas oficinas tipográficas instaladas na cidade de São Paulo entre 1827 e 1927. Disponível em https://www.fau.usp.br/tipografiapaulistana

\section{Sobre as autoras}

Camila C. S. Flores, pesquisadora de Iniciação Científica, USP, Brasil

<camilacatarinaflores@usp.br>

Priscila L. Farias, Professora Associada, USP, Brasil <prifarias@usp.br> 